\title{
Medicinal Uses of Murraya koenigii and Aegle marmelos for Fertility Augmentation in Animals: A Review
}

\author{
Ravi Dutt $^{1 *}$, Jasmer Dalal ${ }^{1}$, Gyan Singh² ${ }^{2}$, S.C. Gahalot ${ }^{1}$ and R.K. Chandolia ${ }^{1}$ \\ ${ }^{1}$ Department of Veterinary Gynaecology and Obstetrics, ${ }^{2}$ Department of Veterinary Clinical \\ Complex, Lala Lajpat Rai University of Veterinary and Animal Sciences, \\ Hisar (Haryana) 125004, India \\ *Corresponding author
}

\section{A B S T R A C T}

\begin{tabular}{|l|}
\hline Ke y w or d s \\
$\begin{array}{l}\text { Aegle marmelos, } \\
\text { Anoestrous, Endometritis, } \\
\text { Murraya koenigii, Repeat } \\
\text { breeding }\end{array}$ \\
\hline Article Info \\
\hline $\begin{array}{l}\text { Accepted: } \\
\text { 06 August } 2018 \\
\text { Available Online: } \\
\text { 10 September } 2018\end{array}$ \\
\hline
\end{tabular}

Key words breedin
The hormonal therapies for the treatment of various reproductive disorders are accused to impair some neuro-endocrine and physiological activities. Besides, the residual effects of hormonal therapy in food animals and their products of public health importance seriously demands minimization of our dependence on hormones for therapeutic purposes. High cost, lack of quick assay facilities, non-availability of commercial preparations with ease and need of veterinary supervision are other limitations with use of hormones for animal fertility management/augmentation purposes. In countries like India, the validation and transferring of traditional/indigenous knowledge to the livestock raising farmers may serve indeed the livestock raisers for better farm economy. Two herbal plants namely Murraya koenigii and A. marmelos have been scientifically tested individually and in combination, for ovarian dynamic studies in rats, goats, cattle and buffaloes. These plants have been reported to be efficacious for the treatment of anoestrous, repeat breeding and endometritis.

\section{Introduction}

Ethno veterinary research has emerged as a fertile field for the generation (or regeneration) and transfer of appropriate and sustainable animal health technologies to rural and even peri-urban livestock raisers everywhere especially in the third world. Ethno veterinary practices still have significant contributions to animal health and are regarded as sustainable veterinary medicine in the new era (Lin et al., 2003). The prefix 'Ethno' stands for traditional or indigenous and imbibes the knowledge passed on verbally from generation to generation. There cannot be any shadow of doubt on the poly valency of ethno veterinary medicines obtained from nook and corners of the world. The ethno veterinary practices, therefore, include all aspects of indigenous practices to prevent and treat a range of livestock diseases. As much as $90 \%$ of the world's population today still relies mainly on local ethno medicine for their health needs (Duke, 1992). Similar figures appear to hold for the livestock sector (McCorkle, 1998). Because of the cost 
of random screening, perhaps only $1 \%$ of the higher plant species that have been used in ethno medicine are subjected to systemic scientific study for their therapeutic value in extract form (Farnsworth, 1983). The World Health Organization (WHO) has recognized the value and imperative need for adopting traditional herbal practices in global health care and recommended all member countries to initiate steps to conserve native medicinal plants and also emphasizes integrating indigenous health care system with modern health facilities (Dalal, 1992).

India and China are two largest countries in Asia which has richest array of medicinal plants. An herbal renaissance is blooming across the world; China is perhaps the only country of the world who has demonstrated the best use of traditional medicine in providing the best health-care to her people. The modern practices have replaced the traditional practices in some parts of the developed world (Tabuti et al., 2003). In Indian subcontinent, the tradition of using plants for treating ailments is very old. India as a whole is the richest source of the medicinal plants which are distributed in almost all parts of the country (Ali, 1994) with wide variation in different climatic zones ranging from alpine to tropical region. It is significant to note that more that $90 \%$ of drugs used in traditional medicines practiced in India come from plants and $70 \%$ of modern medicines originate from natural resources and plants (Mukherjee and Wahile, 2006). It has been estimated that more than one third of the plant drugs mentioned in pharmacopeia of the world grow in state of nature in this country. Pharmaceutical companies engaged in the production of plant-based products showed around $15 \%$ of average growth rate (Kumar, 2003).

Existing hormonal therapies used for treatment of gynaecological disorders are believed by the masses to render harmful effects and are "accused" to impair some physiological activity and thus mitigates another disorders (Jadhav and Bhutani, 2005). Residual effects of hormone therapy in food animals and their products of public health importance seriously demands minimization of our dependence on hormones for therapeutic purposes. High cost, lack of quick assay facilities, non-availability of commercial preparations with ease and need of veterinary supervision are other limitations with use of hormones for animal fertility management / augmentation purposes. Herbal remedies may offer a potent alternative of hormones (Jadhav and Bhutani, 2005) and are low cost, efficacious, socially acceptable and mostly are the only available means (Reddy, 2008) with minimal side effect. Validation and transferring of traditional / indigenous knowledge to the livestock raising farmers would serve indeed the people of developing countries (Gesler, 1991).

There are two approaches to develop efficacious phytotherapies. One is phytochemical approach which emphasizes the development of pure phytochemicals as drugs. In general, it is expensive and time consuming. The second approach is phytotherapeutic approach wherein crude plant preparations, (extracts, active fractions or mixtures of them) or ayurvedic types of formulations can be used as drugs with modern standards of safety and efficacy which is cost-effective and more relevant to our conditions (Subramaniam, 2001). Plants in their crude form show combination of activities and huge potential as a source of new drug (Gilani and Rahman, 2005). The active principles of plants may be carbohydrate, glycosides, tannins, lipids and alkaloids (Ramchandran and Mehtani, 1990). Herbal combinations might exhibit significant effects as a result of synergistic or additive actions of their active principles (Ramteke et 
al., 2008). Aegle marmelos (bel) and Murraya koenigii (curry), medicinal plants have currently drawnmany research attention for various reproductive ailments in farm animals (Mehrotra, 2002; Jondhale, 2007; Kumar, 2008, Dutt et al., 2010, 2011; Kumar et al., 2016; Kumawat et al., 2016; Rautela et al., 2017, 2018). Individually the medicinal plants M. koenigii (Mehrotra, 2002) and A. marmelos (Jondhale, 2007 and Kumar, 2008) and in combination (Dutt et al., 2010; 2011; Kumar et al., 2016; Baitule et al., 2016) have been used to augment the reproductive function in laboratory rats and anestrus goats, cattle/buffalo.

\section{Botanical description, chemical constituents and biological properties of Murraya koenigii}

It is a genus of shrubs or small trees distributed from South and East Asia to Australia.

\section{Murraya koenigii (L.) Spreng.}

Kingdom: Plantae

Division: Magnoliophyta

Class: Magnoliopsida

Order: Sapindales

Family: Rutaceae

Genus: Murraya

Species: koenigii

\section{Common terminology}

Tamil: Karivempu, Karuveppilei

Hindi: Kathnim, Mitha neem, Kurrypatta,

Assamese: Narsinghs, Bisharhari,

Bengali: Barsanga, Kariphulli

Gujarathi: Goranimb, KadhiLimdo

Kannada: Karibevu

Malayalam: Karriveppilei

Marathi: Karhinimb, Poospala,

Oriya: Barsan, Basango,

Punjabi: Curry patta
Sanskrit: Krishna nimba

Telugu: Karipedu

\section{Botanical description}

M. koenigii (Linn.) Spreng., (Family Rutaceae) is commonly known as curry leaf plant or Indian curry leaf plant, is a highly valued plant for its characteristic aroma and medicinal properties. Its leaves are extensively used in making curries, chutneys especially south Indian dishes. Its leaves are used to prepare curry powder which is an important export commodity of India causing handsome earning of foreign exchange to country, every year. M. koenigii is a deciduous aromatic shrub or small tree upto $6 \mathrm{~m}$ in height and 15$40 \mathrm{~cm}$ in diameter. It grows wild and found almost throughout India upto an altitude of $1500 \mathrm{~m}$. Leaflets alternate with leaves 10-20 foliate and bark dark brown or almost black.

\section{Major chemical constituents}

\section{Alkaloids}

The leaves of $M$. koenigii yielded a number of alkaloids including koenigicine apart from koenimbine (Kureel et al., 1969), cyclomahanimbine, bicyclomananimbine and mahanimbidine. The hexane extract yielded mahanimbine, girinimbine and two more alkaloids isomahanimbine and koenimbidine (Joshi et al., 1970). Mahanine, an alkaloid has been isolated from the leaves of the plant and studied in detail by Fidrous (1988).

\section{Amino acids}

The free amino acids present in the leaves are asparagine, glycine, serine, aspartic acid, glutamic acid, threonine, alanine, proline, tyrosine, tryptophan, Y-amino butyric acid, phenylalanine, leucine, isoleucine and traces of ornithine, lysine, arginine and histidine (Anon, 1962). 


\section{Minerals and vitamins}

The leaf extract of M. koenigii was found to contain $66.3 \%$ moisture, $6.1 \%$ protein, $1 \%$ fat (ether extract), 16\% carbohydrate, $6.4 \%$ carbohydrate and $4.2 \%$ mineral matter. It contains $810 \mathrm{mg}$ calcium, $600 \mathrm{mg}$ phosphorus, $3.1 \mathrm{mg}$ iron, $12,600 \mathrm{IU}$ carotene, $2.3 \mathrm{mg}$ nicotinic acid and $4 \mathrm{mg}$ Vit. C/100 g of leaf extract (Kumar et al., 1999). It is evident that plant is rich source of Vit. A, calcium and phosphorus.

\section{Biological properties}

Effect of $M$. koenigii was studied on carbohydrate metabolism in rats by Khan et al., (1995). It showed significant hypoglycaemic action. There was an increase in concentration on hepatic glycogen and glycogenesis and decease in glycogenolysis and gluconeogenesis.

Curry leaf as a feed supplement in rats $(10 \%$ of diet for 3 months) caused reduction in total serum cholesterol, low density lipid and lipoprotein and increase in high density lipid (Khan et al., 1996). Antifungal activity has been reported from essential oil of its leaves (Pandey and Dubey, 1997).

Crude ethanol extract of leaves and the chloroform soluble fraction showed promising antibacterial activity against all type of tested bacteria (Nutan et al., 1998). Tender and mature leaves of the plant are reported to possess activities of enzymatic antioxidants (catalase, peroxidase and superoxidase dismutase).

This suggests that leaves would render the cell protection against oxidative damage (Padma et al., 1998). Kesari et al., (2005, 2007) observed the hypoglycemic effects of aqueous extract of leaves of M. koenigii on normal and alloxan diabetic laboratory animals.

\section{Medicinal uses}

The plant is having several curative properties in traditional therapy. The leaves, root and bark of the plant are considered tonic, stomachic and carminative (Raghunathan and Mitra, 1982) and are used in medicine. An infusion of toasted leaves is used for checking vomition. The leaves are given in the decoction with bitters as a febrifuge. The juice of root is given to the patients suffering from pain associated with kidneys (Brooker and Gajjar, 1953).

The leaves and root are bitter, acrid, cooling alexeteric, anthelmentic, analgesic, cures piles, allay heat of the body thirst, inflammation, itching, useful in leucoderma and blood disorders. The green leaves are described to be eaten raw for the cure of dysentery and when they are boiled in milk and ground, they form a good application to cure poisonous bites and eruptions (Nadkarni, 1954).

Sundersanam et al., (1995) found the use of plant leaves in folk herbal medicine to promote fertility in animals. M. koenigii alone was equally effective in inducing fertility in anestrus buffaloes, as was in combination with mineral mixture and low dose of $\mathrm{GnRH}$ injection (Umashanker et al., 2006). Hegde et al., (2002) studied the use of M. koenigii for the treatment of repeat breeding in dairy animals and recorded $80 \%$ efficacy of $M$. koenigii. $M$. koenigii has the potential to stimulate the ovarian function in rats and encouraging treatment response in acyclic goats and cattle, in terms of estrus induction and conception (Mehrotra, 2002).

Similarly, Satheshkumar and Punniamurthy (2005) recorded that supplementation of $100 \mathrm{~g}$ of $M$. koenigii leaves for 30 days daily in rural crossbred heifer results induction of estrus in $60 \%$ of animals with elevation in serum calcium and phosphorus concentrations. 
Botanical description, chemical constituents and biological properties of Aegle marmelos

It is commonly found in the sub-Himalayan tract up to an altitude of $1200 \mathrm{~m}$ in the dry deciduous forests of central and southern India.

Aegle marmelos (L.) Spreng.

Kingdom: Plantae

Phylum: Tracheophyta

Class: Magnoliophyta

Sub class: Rosidae

Order: Sapinales

Family: Rutaceae

Genus: Aegle

Species: marmelos

\section{Common terminology}

English: Golden Apple, Bengal Quince

Hindi: Bel (Bael), Belgiri, Beli

Kannada: Belpatra, Bilva, Maaluraa

Bengali: Bel (Bael)

Sanskrit: Bilva, Shivadrumaa

Tamil: Vilva Marum, Vilvama

Telugu: Bilva, BilvaPandu, Maaredu

Urdu: Bel, Bel Kham, Belgiri

Malayalam: Maaredy

Marathi: Bel (Bael), Vel

Oriya: Belo

Assamese: Bel (Bael)

Gujarati: Bel, Belli, bili

\section{Botanical description}

It is a medium-sized, deciduous tree, up to 7.5 $\mathrm{m}$ in height and the branches are armed with about $2.5 \mathrm{~mm}$ long sharp spines.

Leaves are glabrous, attenuate and trifoliate, flowers are large, greenish-white and sweet scented with numerous seeds. The ripe fruits are large and sub spherical, greenish-white with a tough woody outer coat. The roots are woody, fairly large and often curved. The bark is corky and light grey in color (Elizabeth, 2002).

\section{Major chemical constituents}

\section{Alkaloids}

The leaves contain alkaloids including aegelenine and aegeline. The roots and aerial parts contain skimmianine (Bhavan, 1992).

Anthraquinones, tannins and triterpenes

7,8-Dimethoxy-1-hydroxy-2-

methylanthraquinone and 6-hydroxy-1methoxy-3-methyl anthraquinone. The fruit contains tannic acid. The tannin content of the fruit and rind is 7-9\% and $18-22 \%$ respectively. The leaves also contain condensed tannins. The roots contain $\beta$ sitosterol and lupeol (Srivastava et al., 1996).

\section{Coumarins}

The fruit contains marmelosin, alloimperation, marmelide and psoralen and the roots umbelliferone, psoralen, xanthotoxin, dimethoxycoumarin, scopoletin. The heartwood yields $\alpha$-xanthotoxol-8-O- $\beta$-Dglucoside and the seeds contain luvangetin (Bharthakur and Arnold, 1989).

\section{Biological properties}

Ponnachan et al., (1993) reported that active principles in A. marmelos leaves extract have similar anti-hyperglycaemic activity to insulin treatment in alloxan induced diabetic rats. Leaf extract of A. marmelos also helps in the regeneration of damaged pancreas ( $\beta$-cells) in diabetic rats (Das et al., 1996). 75\% methanol extract of leaves of A. marmelos is found to reduce blood sugar in alloxan diabetic rats (Sabuand Kuttan, 2004). Aqueous and alcoholic extracts of leaves given orally 
produced significant hypoglycaemia in normal fasted rabbits, but not the petroleum ether extract. Aqueous extract showed cardiac stimulant, smooth muscle relaxant and uterine stimulant properties (Ayushveda.com).Kesari et al., (2006) reported the hypoglycemic and anti-hyperglycaemic activity of $A$. marmelos seed extract in normal and diabetic rats. The leaf of the A. marmelos plant also has hepatoprotective effect (Singanan et al., 2007).

\section{Medicinal uses}

It is used in reproductive disorders like miscarriage, retention of the placenta, repeated estrus in cows and buffaloes, vaginal haemorrhages, orchitis and in addition, milk fever etc. The fruits, leaves, roots and bark are used in folk veterinary medicine to treat wounds, burns, poisoning and disorders of the digestive systems including dysentery, enteritis and intestinal lesions, tympanitis and for flat and thread worms (Elizabeth, 2002). Leaves are used for the induction of estrus in large animals (Koradia, 1995). Effect of $A$. marmelos in rats was examined by Jondhale (2007), who reported that it significantly advances onset of puberty and results in higher ovarian and uterine weight, increased large surface follicles and number of ovulations. Kumar (2008) recorded enhanced fertility in anestrus goats and buffaloes upon treatment with $A$. marmelos leaves.

Potency has been tested for in-vitro antibacterial effect against a number of Gram positive and negative bacteria obtained from pure laboratory culture (Abirami et al., 2014, Yesaswini et al., 2014) coincidentally reported to be associated with bacterial endometritis in cattle (Bhat et al., 2014).

Table.1 In-vitro antibacterial activity of different extracts of A. marmelos and M. koenigii against various bacteria isolated from endometritic cows

\begin{tabular}{|c|c|c|c|c|c|c|c|}
\hline \multirow{3}{*}{ Organism } & \multicolumn{6}{|c|}{ Zone of inhibition(mm) } & \multirow[t]{3}{*}{ Ciprofloxacin } \\
\hline & \multicolumn{3}{|c|}{ Aqueous extract } & \multicolumn{3}{|c|}{ Ethanolic extract } & \\
\hline & $\mathrm{AM}$ & MK & $\mathrm{AM}+\mathrm{MK}$ & AM & MK & $\mathrm{AM}+\mathrm{MK}$ & \\
\hline Bacillus spp. & 6 & 8 & 10 & 10 & 12 & 14 & 22 \\
\hline Corynebacterium spp. & - & 6 & 9 & 10 & 14 & 13 & 20 \\
\hline E. Coli & - & 6 & 10 & 9 & 11 & 14 & 26 \\
\hline Staphylococcus spp. & 6 & 7 & 13 & 10 & 17 & 16 & 26 \\
\hline Salmonella spp. & - & - & - & 4 & 7 & 9 & 18 \\
\hline
\end{tabular}

AM: A. marmelos extract; MK: M. koenigii extract; AM + MK, A. marmelos and M.koenigii extracts incombination

Clinical uses of Murraya koenigii and Aegle marmelos in fertility augmentation

\section{Ovarian dynamics in rodents}

The oral administration of methanolic extracts of M. koenigii@500 mg/kg b.w. advanced the age of attainment of puberty, relative ovary and uterus weight and the number of ovarian surface follicles in female Wistar albino rats from 20 to 70 days of age. The significant advancement in the mean age of attainment of puberty was observed along with increase in number of surface follicles on both the ovaries attributed due to the effects of phytoestrogens present in the methanolic extracts of M. koenigii (Nandini et al., 2010).

The effect of $50 \%$ ethanolic extract of $A$. marmelos was examined on the onset of puberty in rats at three dose levels i.e. 100, 300 and $1000 \mathrm{mg} / \mathrm{kg}$ b.w. based on LD50 
studies. Extracts were administered orally from day 26 to 35 of age and induction of vaginal opening was used as an index of puberty and a significantly earlier onset of puberty was recorded (Jondhale et al., 2009a). Similarly, $50 \%$ ethanolic extracts of $A$. marmelos @1000 mg/kgb.w. in same age group of rats resulted in significantly higher uterine weight, large surface follicles and serum estrogen concentrations. The number of ovulations and serum progesterone concentration recorded in treated animals also depicted favourable effect of plant extract. It may be concluded that $A$. marmelos has potential to positively influence the ovarian function in rats (Jondhale et al., 2009b).

\section{Anestrous}

In a study, Dutt et al., (2010) with $M$. koenigii and A. marmelos combination treatment in acyclic goats reported induction of estrus in $85.71 \%(6 / 7)$ animals at a mean interval of $5.33 \pm 0.60$ days after end of treatment ( 9 days) out of which $83.33 \%$ (5/6) conceived in same estrus. The duration of estrus in responded does in control and treatment group was recorded as 24 and $16.0 \pm 1.73$ hours, respectively. $M$. koenigii treatment alone resulted in expression of estrus in 50\% (3/6) of anestrous goats on $18.66 \pm 2.18$ days from end of treatment with $100 \%$ ovulation rate (Mehrotra, 2002). On the other hand, Kumar (2008) recorded estrus induction in $57.14 \%$ (4/7) acyclic goats after treatment with $A$. marmelos with a period of $6 \pm 1.15$ days following end of treatment and conception in all the animals. Treatment with M. koenigii and $A$. marmelos combination led to induction of estrus comparatively at shorter interval of time. The induction of estrus with $M$. koenigii and A. marmelos combination was higher as compared to individually $M$. koenigii (Mehrotra, 2002) and A. marmelos treated goats (Kumar, 2008). Percent conception with A. marmelos treatment alone had been recorded relatively lesser (Kumar, 2008) compared to M. koenigii and A. marmelos combined treatment (57.14 vs. $71.43 \%)$. Furthermore, Dutt et al., (2012) in acyclic goats found that the mean value of triiodothyronine was higher $(\mathrm{P}<0.05)$ on day 8 , 12 and $16 \quad(1.78 \pm 0.06,2.32 \pm 0.20$ and $2.10 \pm 0.28 \mathrm{ng} / \mathrm{ml})$ post treatment with $M$. koenigii and A. marmelos combination, compared to control $(1.24 \pm 0.33,1.03 \pm 0.15$ and $1.09 \pm 0.20 \mathrm{ng} / \mathrm{ml}$ ). The increasing levels $(\mathrm{P}>0.05)$ of peripheral thyroid hormones with resumption of cyclicity $(60 \%)$ between day 8 16 post treatment provides evidence that of tri-iodothyronine and thyroxine might be metabolic signals triggering onset of ovarian cycle (Riest et al., 2003).

In another study, Dutt et al., (2011) examined the effect of combination treatment of $M$. koenigii and A. marmelos on restoration of fertility in anestrous buffaloes. Effective 50\% ethanolic extract doses of both the plants were extrapolated from rats $(1000 \mathrm{mg} / \mathrm{kg})$ to buffaloes using dose equivalent system and converted into powder form based on per-cent yield. Final doses were prepared by mixing of half of the calculated dose of both the plants on body weight basis. After treatment for 9 days, estrus was induced in 60\% (6/10) animals with a mean interval of $9.33 \pm 1.11$ days from end of experiment followed by $66.67 \%$ (4/6) pregnancy confirmation on day 45 post mating. After treatment with $M$. koenigii and A. marmelos for 9 days as per Dutt et al., (2011), the growth rate of large follicles was faster $(\mathrm{P}<0.05)$ in herbs treated $(0.55 \mathrm{~mm} /$ day $)$ than control $(0.25 \mathrm{~mm} /$ day $)$ delayed pubertal buffaloes heifers, it was concluded that supplementation of $A$. marmelos and $M$. koenigii can influence the growth processes of large follicles by the attainment of dominance, accelerated growth rate, preovulatory size and the process of ovulation(Kumar et al., 2016). The estrus response was recorded as 33.33, 50.00, 75.00, 
and $33.33 \%$ in treatment with A. marmelos, M. koenigii, A. marmelos plus $M$. koenigii and control groups, respectively having six animals in each group. In animals treated with combination of both the plants, serum calcium was found significantly $(\mathrm{p}<0.05)$ higher on day 8 post-estrus as compared to other groups at a similar interval. In addition, the ovulation and conception rates were also comparatively better in the group treated with combination of both plants.

Das et al., (2016) examined the estrus induction response and fertility performance in delayed pubertal cattle heifers treated with A. marmelos in combination with $M$. koenigii. A total of 11 heifers were treated as per Dutt et al., (2011) and six heifers were kept as untreated control. Six out of $11(54.1 \%)$ heifers in treatment group and 1 out of 6 $(16.7 \%)$ in control group exhibited standing estrus. All these estrus heifers were inseminated and conceived.

In delayed pubertal cattle heifers, the supplementation of $A$. marmelos and M.koenigii leave powder induced behavioral estrusin higher percentage $(92.3 \%$ ) within day 4-26 following start of treatment as compared to untreated heifers $(46.2 \% ; \mathrm{p}<0.05)$. The mean interval between initiations of herb treatment and exhibition of behavioral estrus was $11.25 \pm 1.91$ days. The conception rate was $61.5 \%$ in herb treated group, whereas the corresponding figure in untreated group was $23.1 \%$. The number of services per conception and calving rate in treatment group was 1.75 and $53.8 \%$, respectively (Kumawat et al., 2016) and the mean interval between the initiation of treatment to onset of estrus was $11.25 \pm 1.91$ days which is comparatively longer than the interval reported earlier under field (8.75-9.84 days) and farm (6 days) conditions (Das et al., 2016).Furthermore, these outcomes corroborated with earlier studies in which $A$.
Marmelos and M. koenigii treatment individually produced fertile estrus in anestrous goat, cattle and buffalo (Mehrotra et al., 2005; Kumar, 2008 and, Satheshkumar and Punniamurthy, 2009). Also, the effect of both the plants in combination was synergized to bring anestrous goat and buffaloes into estrus (Dutt et al., 2010, 2011).

\section{Endometritis}

Recently, Rautela et al., (2017) used aqueous and ethanolic extract $(250 \mathrm{mg} / \mathrm{ml})$ of $M$. koenigii and A. marmelos prepared as per the Firdaus et al., (2014) and Akinnibosun and Umufo (2015), respectively, for investigating the in-vitro antibacterial effects of the extract of both the leaf either alone or in combination on the bacterial species isolated from the cows suffering from endometritis. The antibacterial activity was tested by agar-well diffusion method (Baskaran et al., 2011). The ethanolic extract showed a better response than the aqueous extract, either alone or in combination. Further, ethanolic extract of leaves in combination showed 50 to $65 \%$ equivalent activity to ciprofloxacin during invitro sensitivity test (Table 1). Based on the in-vitro anti-bacterial sensitivity, the study showed rays of hope for the future in-vivo antibacterial potential of $A$. marmelos and $M$. koenigii for the treatment of bacterial endometritis. In an another study Rautela et al., (2018), investigated the antibacterial, antiinflammatory and antioxidant effects of leaves of A. marmelos and M. koenigii in 16 repeat breeder cows due to endometritis. The diagnosis was confirmed by endometrial cytology using $>5 \%$ polymorphonuclear (PMN) as the cut-off point. Cows in the treatment group $(\mathrm{n}=6)$ were supplemented with $200 \mathrm{gm}$ of $A$. marmelos and $M$. koenigii leaf powder daily for 9 days through oral route. The antibacterial, antiinflammatory and antioxidant effects were assessed by evaluating the changes in 
bacterial load, PMN cell count and oxidative parameters like malondialdehyde (MDA), ascorbic acid (ASCA), reduced glutathione (R-GSH), superoxide dismutase (SOD), and total antioxidant capacity (TAC) etc. respectively. Results showed significant reduction in the bacterial load and PMN cell count in the herb supplemented cows. The MDA concentration decreased drastically, whereas ASCA and R-GSH concentrations and TAC increased significantly in herb supplemented cows as compared to control. Although the SOD activity was not significantly different between the groups, there was a tendency of higher activity in herb supplemented cows. In conclusion, $A$. marmelos and $M$. koenigii reduce the bacterial load and inflammation in endometritic dairy cows with a concurrent increase in the endogenous antioxidants.

Studies concerning Murraya koenigiiand Aegle marmelos individually or in combination revealed efficacy of both the plants in terms of induction of estrus, ovulation and pregnancy establishment in anestrus goats, cattle and buffaloes. It may be speculated that as a result of plants treatment FSH from anterior pituitary or other mimicking active principles might have been triggering the follicular dynamics by enhancing the follicular recruitment, selection and rescuing the atresia of follicles. Favourable effects in terms of estrus induction, ovulation, pregnancy establishment and shorter time period taken in induction of estrus are exhibited compared to individual plant treatment which could be a reflection of synergistic actions of plant active principles. The active principles seem to operate either through mimicking gonadotrophins activity or stimulating the central mechanism for endogenous release of gonadotrophins along with possibility of local action, requiring further more detailed studies. It is indicated also indicated that both the plants have anti- bacterial properties that might have resulted in reduction of bacterial load in and inflammation in endometritic dairy cows with a concurrent increase in the endogenous antioxidants. Further research to identify the active ingredients of both the plants is now need of the hour.

\section{References}

Abirami, S. K. G., Vivekanandhan, K., Hemanthkumar, R., Prasanth, S. and Ravi Kumar J. (2014). Study of antimicrobial potential of A. marmelos. Journal of Medicinal Plants Studies. 2: 113-16.

Akinnibosun, F.I. and Umufo, J. A. (2015). Assessment of the phytochemical and antibacterial properties of the synergy of Murraya koenigii and Telfaria occidentalis ethanolic leaf extracts. International Journal of Research Studies in Bioscience. 3: 80-89.

Ali, M. (1994). In: Textbook of pharmacognosy. CBS Publisher, New Delhi, India, pp. 14

Anon (1962). Wealth of India: a dictionary of Indian raw materials and industrial products. Vol.6: L-M, Council of Scientific and industrial Research, New Delhi.

Baitule, M.M., Gawande, A.P., Kumar,U., Sahatpure, S.K., Patil, M.S. and Baitule, M.M. (2016). Effect of A. marmelos and $M$. koenigii in treatment of delayed pubertal buffaloes heifers. Veterinary World. 9(12): 1375-1380.

Baskaran, C., Bai, V. R. and Kanimozhi, D. (2011). Screening for antimicrobial activity and phytochemical analysis of various leaf extract of Murraya koenigii. International Journal of Research in Ayurveda and Pharmacy. 2: 1807-10.

Bharthakur, N.N. and Arnold, N.P. (1989). Central organic and inorganic 
constituent in bel (A. marmelos) fruit. Tropical Agriculture. 66(1): 65.

Bhat, F. A., Bhattacharyya, H. K. and Hussain, S. A. (2014). White side test: A simple and rapid test for evaluation of non-specific bacterial genital infections of repeat breeding cattle. Veterinary Research Forum. 5: 177-80.

Bhavan, B. (1992). A. marmelos. In: Bhartiya Vidya Bhavan Selected medicinal plants of India. Chemexil, Mumbai.

Brooker, R. and Gajjar, K.T. (1953).Phagocytic response in guinea pig to certain indigenous medicinal plant extract. Curr. Sci., 22: 44-45.

Dalal, K.C. (1992). Present status and perspectives of medicinal plants. J. Res. Edu. Ind. Med., July- Sept., 15-20.

Das, A.V., Padayatti, P.S. and Pauose, C.S. (1996). Effect of leaf extract of $A$. marmelos (L.) Correa ex Roxb. On histological and ultrastructural changes in tissues of streptozotocin induced diabetic rats. Indian Journal of Experimental Biology. 34(4): 345-347.

Das, G.K., Mehrotra, S., Narayanan, K., Kumawat, B.L., De, U.K and Khan, T.A. (2016). Estrus induction response and fertility performance in delayed pubertal heifers treated with $A$. marmelos and M. koenigii. Journal of Animal Research. 6 (1). 921-926.

Duke, J.A. (1992). Tropical botanical extractives. In: Plotkin, M., Famolare, L., editors: Sustainable harvest and marketing of rain forest products, Covelo, Califand and Washington, DC, Island Press for Conservation International.

Dutt, R., Mehrotra, S., Hoque, M., Uma, Shanker, Singh, G., Agarwal, S.K., Das, G.K. and Singh, S.K. (2010). Effect of $M$. koenigii and A. marmelos combination on resumption of fertility in anestrous goats. J. Appl. Anim. Res., 38: $275-278$.
Dutt, R., Mehrotra, S., Shanker, U. and Singh, G. (2011). Effect of M. koenigii and A. marmelos feeding on anestrus buffaloes. Indian Journal of Animal Reproduction. 32 (1): 47-49.

Dutt, R., Mehrotra, S., Singh, G and Shankar, U. (2012). Serum tri-iodothyronine and thyroxine profile in $M$. koenigii and $A$. marmelos combination treated acyclic goats. Haryana Veterinarian. 55:53-55.

Elizabeth M. Williams (2002). Major Herbs of Ayurveda: Compiled by Dabur Research Foundation and Dabur Ayurvet Limited. pp. 25-29.

Farnsworth, N.R. (1983). The NAPRALERT data base as an information source for application to traditional medicine. In Bannerman, R.H., Burton, J., WenChieh, C., editors; Traditional medicine and health care coverage, Geneva, W.H.O.

Firdaus, S. B., Ghosh, D., Chattyopadhyay, A., Dutta, M., Paul, S., Jana, J., Basu, A., Bose, G., Lahiri, H., Banerjee, B., Pattari, S., Chatterjee, S., Jana, K. and Bandyopadhyay D. (2014). Protective effect of antioxidant rich aqueous curry leaf (M. koenigii) extract against gastrotoxic effects of piroxicam in male Wistar rats. Toxicology Reports. 1: 9871003.

Firdous, S. (1988). NMR studies on mahanine. Fitoterapia 59: 494-495.

Gesler, W.M. (1991). The cultural Geography of Health Care. University of Pittsburgh Press, Pittsburgh, Philadelphia, USA.

Gilani, A.H. and Rahman, A. (2005). Trends in ethno pharmacology. J. Ethno pharmacol., 100: 43-49.

Hegde, G.V., Nimbalka, G.S., Hegde, G.S and Naik, K. (2002). Use of herbal plants for repeat breeding problem in dairy animals. Indian Vet. J., 79: 861862. 
Jadhav, A. N. and Bhutani, K.K. (2005). Ayurveda and gynaecological disorders. J. Ethno pharmacol., 97: 151-159.

Jondhale, N.S. (2007). Effect of A. marmelos and Ficusreligiosaon the ovarian function in rats and follicular dynamics in goat. M.V.Sc. Thesis, Indian Veterinary Research Institute, Izatnagar (Deemed University), Bareilly. India.

Jondhale, N.S., Mehrotra, S., Agarwal, S.K., Singh, S.K. and Deori, S. (2009a). Effect of A. marmelos and Ficus religiosa on the onset of puberty in immature female rats. Indian Vet. Journal. 86(4):353-355

Jondhale, N.S., Mehrotra, S., Agarwal, S.K., Singh, S.K., Das, G.K., Kumar, D., Shanker, U., Deori, S. (2009b). Effect of A. marmelos and Ficus religiosa leaves extracts on the ovarian function in rats. Indian Vet. J., 86(4):353-355.

Joshi, B.S., Kamat, V.N. and Gawad, D.H. (1970). The structure of girinimbine, mahanimbine, isomahanimbine, koenimbidine and murrayacine. Tetrahedron. 26: 1475.

Kesari, A. N., Gupta, R. K and Watal G (2005).Hypoglycemic effects of $M$. koenigii on normal and alloxan diabetic rats. J. Ethno Pharmacol., 97(2): 24751.

Kesari, A. N., Gupta, R. K., Singh, S. K., Diwakar, S and Watal, G (2006). Hypoglycemic and anti-hyperglycaemic activity of $A$. marmelos seed extract in normal and diabetic rats. J. Ethno pharmacol., 107(3): 374-379.

Kesari, A. N., Kesari, S., Singh, S. K., Gupta, R.K and Watal, G. (2007). Studies on glycemic and lipidemic effect of $M$. koenigii in experimental animals. $J$. Ethno pharmacol., 112(2): 305-379.

Khan, B.A., Abrahm, A and Leeamma, S (1995). Hypoglycemic action of $M$. koenigii (curry leaf) and Brassica juncea (Mustard). Indian J. Biochem. Biophy., 32: 106-108.

Khan, B.A., Abrahm, A and Leeamma, S. (1996). Biochemical response in rats to the addition of curry leaf (M. koenigii) and mustard seed (Brassica juncea) to the diet. Plant Food for Human Nutrition. 49(4): 295-299.

Koradia, D.T. (1995). Implement for interculturing and earthing up. Honey Bee., 6(3): 12.

Kumar, A. (2003). Plant based medicines in India. Press Information Bureau, Govt. of India, New Delhi, India.

Kumar, B., Sachan, V., Kumar, A., Singh, V., Das, G.K., and Saxena, A. (2016). Effect of Supplementation of $A$. marmelos and $M$. koenigii on the follicular development in delayed pubertal sahiwal heifers. Journal of Animal Research. 6(6): 1047-1052.

Kumar, D., Tripathi, H.C., Tandon, S.K., Chandra, S., Jawaharlal, and Malik, J.K., (1999). Folk-Iore herbal veterinary medicines employed in reproductive disorders and for enhancing milk production in India and Nepal - An update. Indian J. Anim. Sci., 69(11): 953-957.

Kumar, R. (2008). Effect of A. marmelos (Bel) and Ficus religiosa (Pipal) on the reproductive performance in anoestrus goat and buffalo. M.V.Sc. Thesis, Indian Veterinary Research Institute, Izatnagar, India.

Kumawat, B.L. Das, G.K., Narayanan, K., Mehrotra, S., Prasad, J.K., Ghosh, S.K. and Kumar, H. (2016). Effect of $A$. marmelos and $M$. koenigii on estrus induction, conception and calving rate in delayed pubertal heifers under field condition. Indian Journal of Animal Reproduction. 37 (2): 17-19.

Kureel, S.P., Kapil, R. S. and Popli, S.P. (1969). New alkaloids from M. koenigii. Spreng. Experimentia., 25: 790. 
Lin, J.H., Kaphle, K., Wu, L.S., Yang, N.Y.J., Lu, G., Yu, C., Yamada, H. and Rogers, P.A.M (2003). Sustainable veterinary medicine for the new era. Review Scientific and Technical Office International Epizootics, 22: 949-964.

McCorkle, C.M. (1998). Ethno veterinary medicine. In: Schoen, A.M., Wynn, S.G., editors: Complementary and Alternative Veterinary Medicine; Principles and Practice.

Mehrotra, S. (2002). Studies on ovarian function using certain medicinal plants in rats, goat and cattle. Ph.D. Thesis, Indian Veterinary Research Institute, Izatnagar (Deemed University), Bareilly. India.

Mehrotra, S., Singh, S.K., Uma Shanker and Agarwal, S.K., (2005). Effect of certain indigenous medicinal plants on ovarian hormone profile and reproductive performance in anoestrus cattle. Indian J. Anim. Reprod., 26: 20-23.

Mukherjee, P. K and Wahile, A. (2006). Integrated approaches towards drug development from Ayurveda and other Indian system of medicines. J. Ethno Pharmacol., 103: 25-35.

Nadkarni, A. K. (1954). In: Indian Materia Medica. Vol 1. Popular prakashan, Bombay.

Nandini, M.S. T. Veena, T. and Swamy, M.S. (2010). Effect of extracts of M. koenigii Spreng. and Morus albalinn. on the age of attainment of puberty and ovarian folliculogenesis in rats. Journal of Basic and Clinical Pharmacy. 1 (4): 203-207.

Nutan, M.T.H., Hasant, A and Rasid, M.A.(1998). Antibacterial and cytotoxic activities of $M$. koenigii. Fitoterapia, 69:173-175.

Padma, P. R., Bhuuvaneshwari, V. and Silambuchelvi, K (1998). The activities of enzymatic antioxidants in selected green leaves. Ind. J. Nutr. Dieteties. $35: 1-3$.
Pandey, V.N and Dubey, N.K (1997). Synergistic activities of extracted plant oils against Pythum apalanidermatum and $P$. debaryanum. Trop. Agric. (Trininad) 74: 164-167.

Ponnachan, P.T.C., Paulose, C.S. and Panikkar, K.R. (1993). Effect of leaf extract of $A$. marmelos on diabetic rats. Indian Journal of Experimental Biology. 31: 345-357.

Raghunathan, K and Mitra, R. (1982). In: Pharmacognosy of indigenous drugs. Central Council for research in Ayurveda and Sidha, New Delhi, Vol. 1, pp. 433-452.

Ramchandaran, K. and Mehtani, S. (1990). Ayurvedic Drugs- The need for current identity. J. Res. Edu. Ind. Med., 9(1):13.

Ramteke, V.D., Vadlamudi, V.P., Waghmare, S.P.,.Handa, A. and Lonare, M.K. (2008). Evaluation of anthelmintic activity of indigenous herbal formulations in goats. Ind. Vet. J., 85: 1157-1159.

Rautela, R., Das, G.K., Prasad, S., Kumar, A., Prasad, J.K., Ghosh, S.K. and Kumar, N. (2017). In-vitro antibacterial potential of aqueous and ethanolic extract of $A$. marmelos and $M$. koenigii leaf on the bacterial strains isolated from endometritic cows. Indian Journal of Animal Sciences. 87 (7): 844-845.

Rautela, R., Das, G. K., Khan,F. A., Prasad, S., Kumar, A., Prasad, J.K., Ghosh, S. K., Dhanze, H., Katiyar, R., Srivastava, S. K. (2018). Antibacterial, antiinflammatory and antioxidant effects of A. marmelos and $M$. koenigii in dairy cows with endometritis. Livestock Science. 214:142-148.

Reddy, K.N. (2008). Ethno botany of Andhra Pradesh: A Review. Ethno botany Leaflets. 12: 305-310.

Reist, M., Erdin, D. K., Euw, D. V., Tschumperlin, K. M., Leuenberger, H., 
Hammon, H. M., Morel, C., Philiponda, C., Zbinden, Y.,Kunzi, N. and Blum, J. W. (2003). Postpartum reproductive function: association with energy, metabolism and endocrine status in high yielding dairy cows. Theriogenology. 59:1707-1723.

Sabu, M.C. and Kuttan, R. (2004).Antidiabetic activity of $A$. marmelos and its relationship with its antioxidant properties. Indian $J$. Physiol. Pharmacol., 48(1): 81-88.

Satheshkumar, S. and Punniamurthy, N. (2005). Effect of M. koenigii (Curry leaves) supplementation on estrus induction and serum calcium and phosphorus concentrations of anestrus heifers (Abstract), XXI Annual Convention of ISSAR and National Symposium on: Recent Trends and Innovations in Animal Reproduction: Nov. $23^{\text {rd }}-25^{\text {th }}$, SKAUST, Jammu. p.p. 100 .

Satheshkumar, S. and Punniamurthy, N. (2009). Oestrus induction by supplementation of Murraya koenigii in anoestrus heifers. Indian J. Anim. Reprod., 30: 66-67.

Singanan, V., Singanan, $M$ and Begum, H. (2007). The Hepatoprotective effect of Bael leaves (A. marmelos) in alcohol induced liver injury in albino rats. Int. $J$. Sci. Tech., 2(2): 83-92.

Srivastava, S. D., Srivastava, S. and Srivastava, S. K. (1996). New anthraquinones from the heartwood of A. marmelos. Fitoterapia. 67: 83.
Subramaniam, A. (2001). The problem and prospects of plant drug research in India: Pharmacogical evaluation of ecotypes in herbal development. Indian J. Pharmacol., 33: 145-146.

Sundersanam, G., Reddy, M.B. and Nagaraju, N. (1995). Veterinary crude drugs in Rayalaseema, A.P., India, Int. J. Pharmacognosy., 33(1): 52-60.

Tabuti, J.R.S., Dhillion, S.S., Lye, K.A. (2003). Ethno veterinary medicines for cattle (Bos indicus) in Bulamogi country, Uganda: plant species and mode of use. J. Ethno pharmacol., 88: 279-286.

Umashanker, Agarwal, S.K., Mehrotra, S.K., Singh, S.K. and Hoque, M. (2006). Restoration of fertility in anestrus buffaloes using $M$. koenigii (Curry leaf plant). XXII Annual Convention and National Symposium on Innovative Technologies for Fertility Enhancement in Livestock, Nov. 10-12, MHOW (M.P) PP-28, pp. 283.

Van Miert, A.S.J.P.A.M. (1986). The use of animals of drug licensed for human use only. In: Comparative Veterinary Pharmacology, Toxicology and Therapy. Eds. Van Miert (A. congress of European Association Vet. Pharmacology and Toxicology, Belgium, MTP press, Limited, Lancaster: 489- 500.

Yesaswini, K.V.S. R., Sneha, R., Sudharshan, J. and Sheik, A. (2014). Evaluation of the antibacterial activity of A. marmelos at different concentrations and temperatures. Helix. 5: 594-99.

\section{How to cite this article:}

Ravi Dutt, Jasmer Dalal, Gyan Singh, S.C. Gahalot and Chandolia, R.K. 2018. Medicinal Uses of Murraya koenigii and Aegle marmelos for Fertility Augmentation in Animals: A Review. Int.J.Curr.Microbiol.App.Sci. 7(09): 645-657. doi: https://doi.org/10.20546/ijcmas.2018.709.077 